\title{
Corrigendum
}

\section{Characterization of the temperate actinophage $\phi$ A7 DNA and its deletion derivatives}

\author{
Luis A. Diaz, Carlos Hardisson and M. Rosario Rodicio
}

Journal of General Microbiology (1991), 137, 293-298

The attP site in Fig. 1(a) was incorrectly positioned; a corrected version of the figure is shown below.

(a)

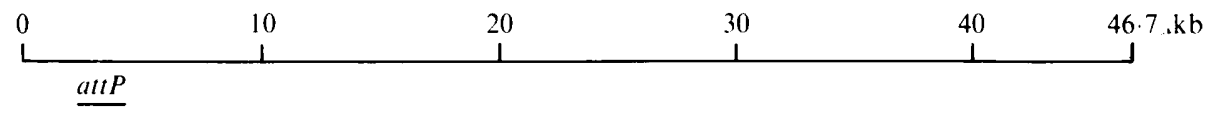

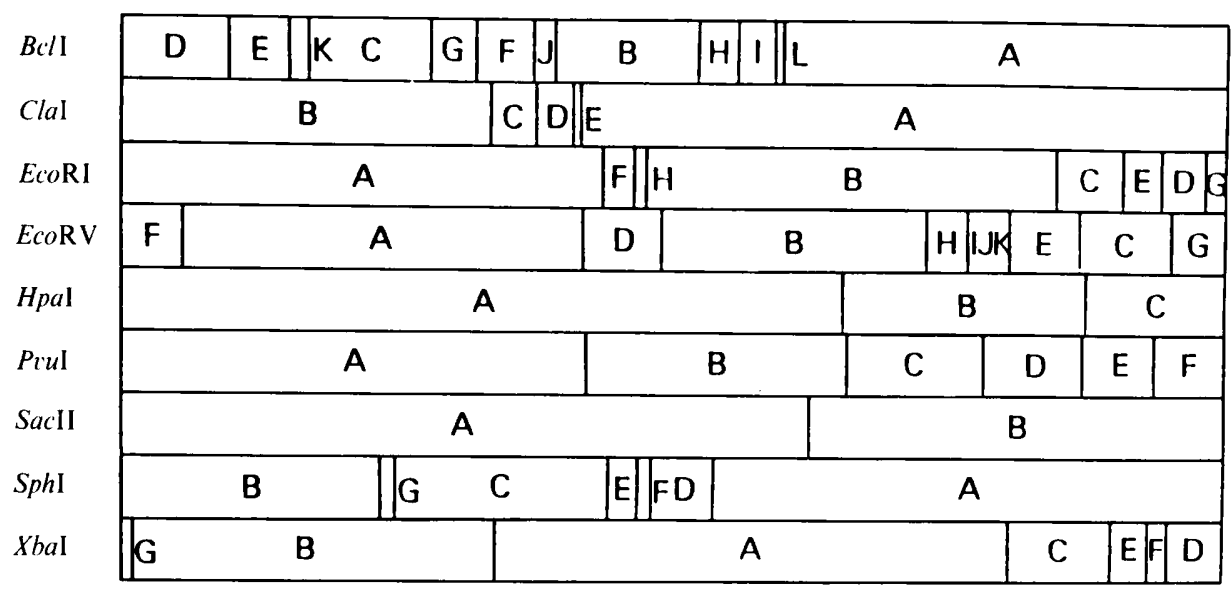

(b)

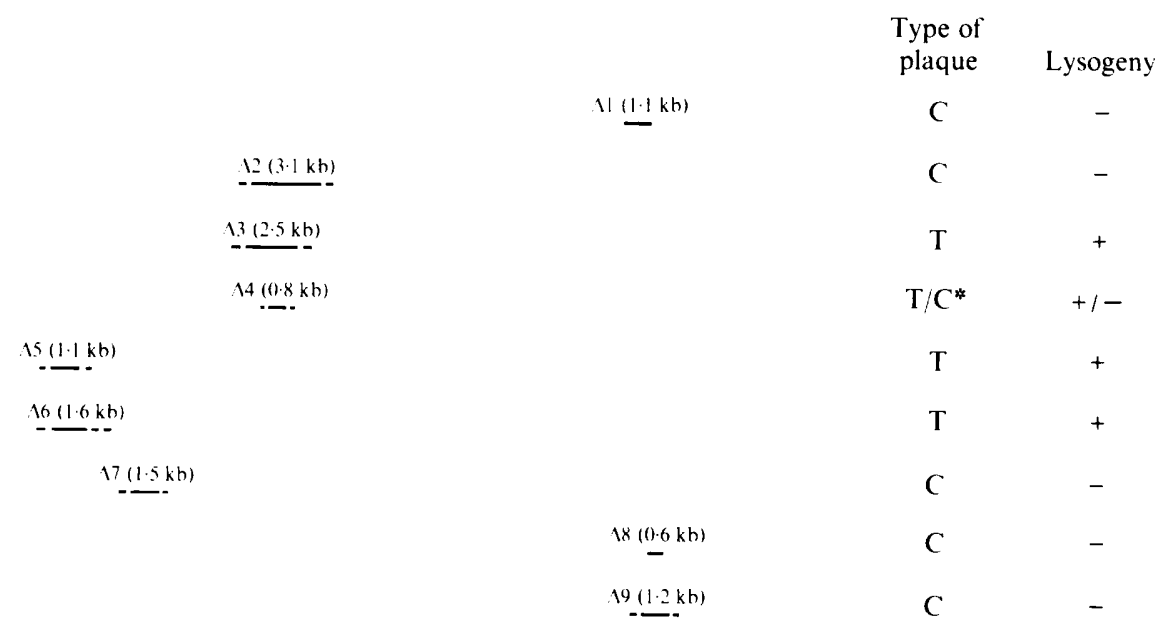

Fig. 1. (a) Restriction map of wild-type $\phi$ A7 DNA. Letters in the block diagrams are fragment designations in order of decreasing size. The precise position of the EcoRV-I, -J and -K fragments was not determined. The DNA contains no sites for BamHI, BglII, HindIII, PstI, PvuII, SacI or SalI. The region established by Southern hybridizations to contain the $a t t P$ site is indicated by the horizontal bar above the map. (b) Location of the deletions in the DNA of phage $\phi \mathrm{A} 7$ and characteristics of the deletion derivatives. The extent of the deletions is indicated by bars below the map (broken lines indicating uncertainty about the exact ends). Lengths of deletions are given in parentheses. C, clear plaques; $T$, turbid plaques; + , ability, - , inability to lysogenize.

* Four independent deletion mutants with identical structure were obtained. Three gave turbid plaques and retained the ability to lysogenize; one gave clear plaques and could not lysogenize $S$. orchidaceus or $S$. albus $\mathrm{P}$. 